Supplementary Information for:

\title{
A paper-based microfluidic device (DON-Chip) for rapid and low-cost deoxynivalenol quantification in food, feed and feed ingredients
}

Qian Jiang, ${ }^{\dagger, \ddagger}$, Jiandong $_{\mathrm{Wu}},{ }^{\S},{ }_{\perp}$ Kang Yao, ${ }^{\dagger}$ Yulong Yin, ${ }^{\dagger}$ Max M. Gong, ${ }^{\amalg}$ Chengbo Yang, ${ }^{*}$ Francis Lin ${ }^{*} \S$

${ }^{\dagger}$ Laboratory of Animal Nutritional Physiology and Metabolic Process, Institute of Subtropical Agriculture, Chinese Academy of Sciences, Changsha, Hunan 410125, P.R. China;

${ }^{\ddagger}$ Department of Animal Science, University of Manitoba, Winnipeg, Manitoba R3T 2N2, Canada;

${ }^{\S}$ Department of Physics and Astronomy, University of Manitoba, Winnipeg, Manitoba R3T 2N2, Canada;

${ }^{\amalg}$ Bock Department of Biomedical Engineering, Trine University, One University Avenue, Angola, IN 46703, USA

${ }^{\perp}$ These authors contributed equally.

* E-mail: Chengbo. Yang@ umanitoba.ca for CBY

* E-mail: Francis.Lin@umanitoba.ca for FL 
Figure S1. Schematic illustration of the portable imaging system. The system includes an XY stage to locate the signal areas, a Z-stage to adjust the focus, and a USB microscope to read the signal. Custom parts were machined to mount these components on an optical breadboard. The portable system was connected to a computer for image acquisition and signal analysis.

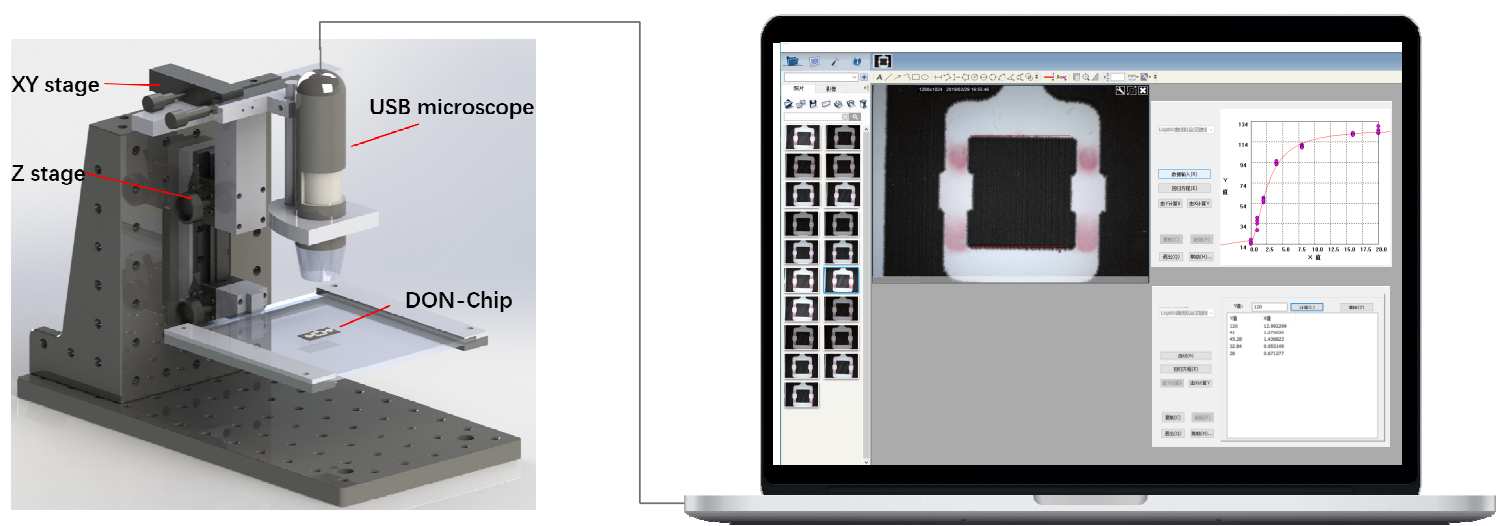


Figure S2. Optimization of channel design in the DON-Chip. The capillary flow speed in different designs was tested. The channel in the initial designs is $1.0 \mathrm{~mm}$ wide (Design 1), $2.0 \mathrm{~mm}$ wide (Design 2; the diamond in the center of the device indicates the horizontal position that separates the T1 area and the T2 area in the test channels). The channel in the optimized design is $1.5 \mathrm{~mm}$ wide with curved corners. After blocking the non-specific binding sites in the channel with $0.2 \%$ bovine serum albumin (BSA), $20 \mu \mathrm{L}$ of PBS was loaded in the loading areas of these chips, and the images were captured after 60 seconds. DON: deoxynivalenol.

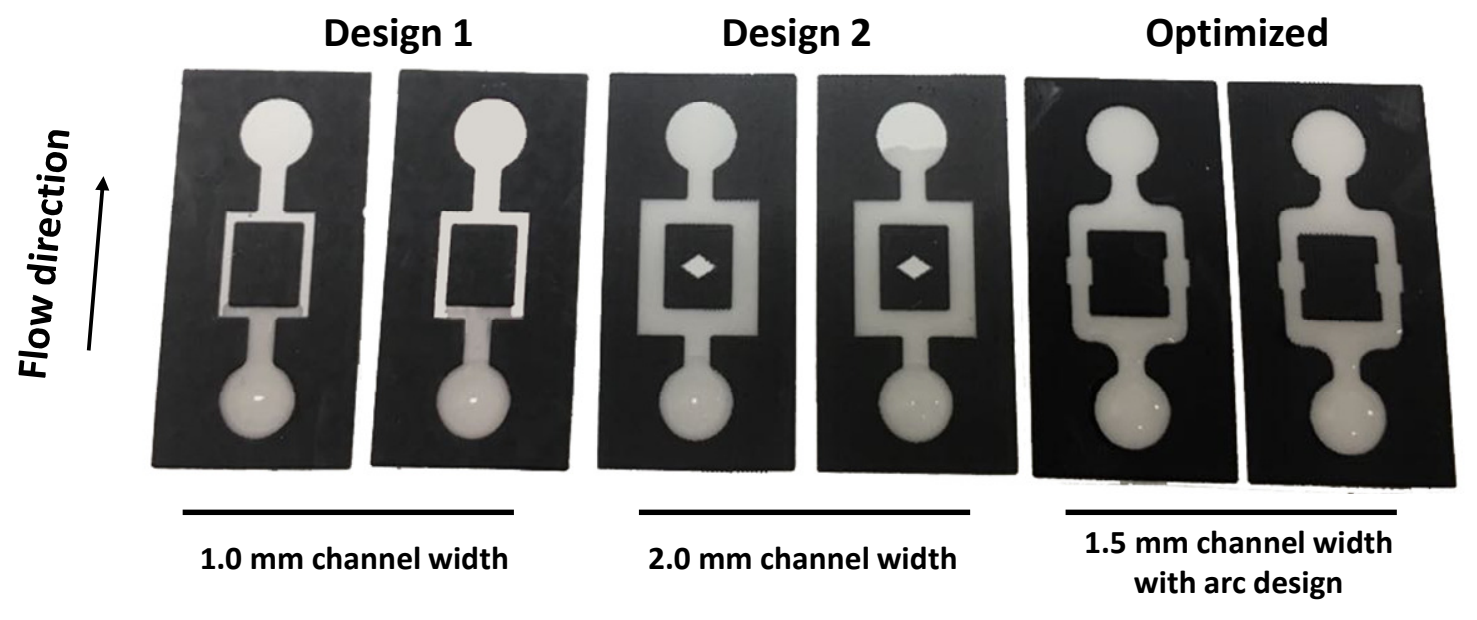


Figure S3. Optimization of DON-BSA concentration in the $\mathrm{T} 1$ area. $0.1 \mu \mathrm{L}$ of 0.475 , 0.950, 1.900 and $3.800 \mu \mathrm{g} / \mu \mathrm{L}$ DON-BSA were deposited in the T1 area of 4 DON-Chips. The T2 areas were deposited with $1.0 \mu \mathrm{g} / \mu \mathrm{L}$ of anti-mouse IgG. During the detection, 20 $\mu \mathrm{L}$ of PBS ( $\mathrm{pH}=7.2)$ was loaded in the conjugate pad of these DON-Chips. DON-BSA, deoxynivalenol conjugated bovine serum albumin.

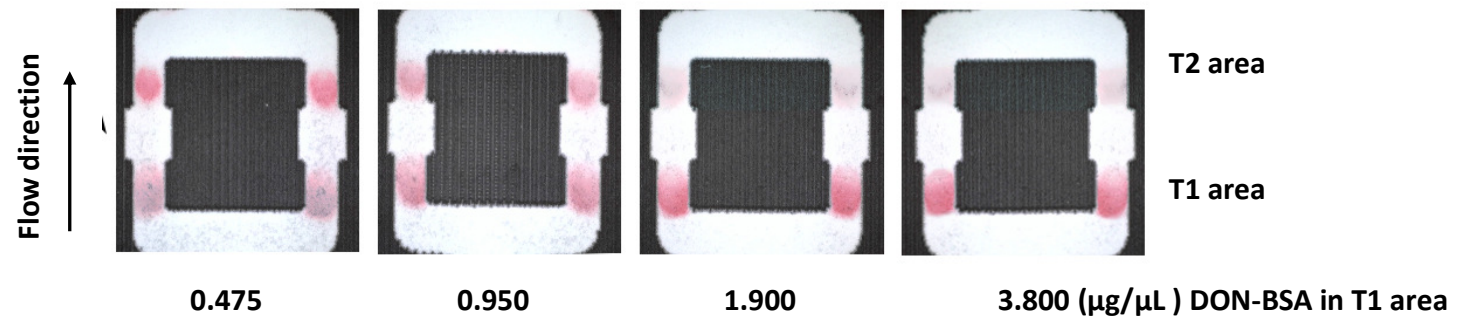


Figure S4. The sum of signal intensity in two detection areas $(\mathrm{T} 1+\mathrm{T} 2)$ in the DONChips when using different concentrations of DON standards ranging from 0 to $20 \mathrm{ng} / \mathrm{mL}$. DON: deoxynivalenol.

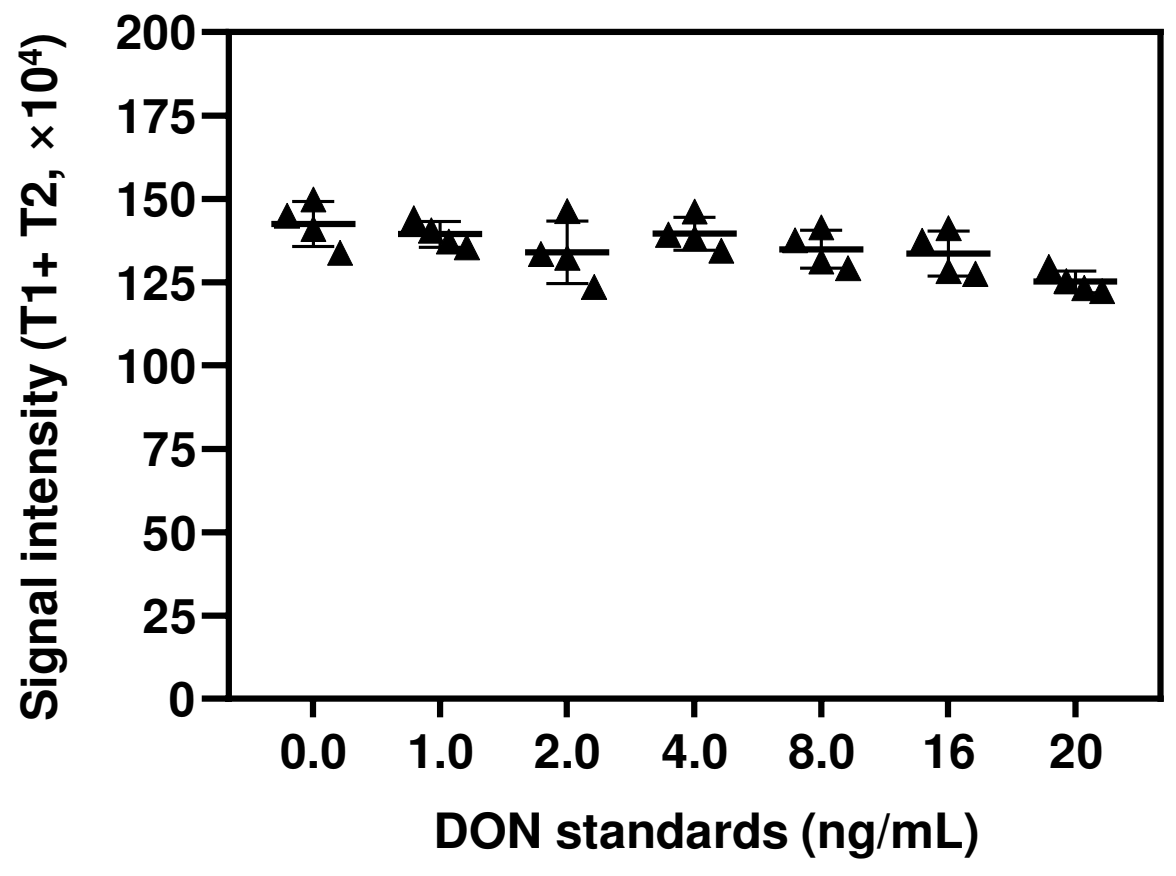


Figure S5. Representative images of the DON-Chips working under the conditions of strong acidity $(\mathrm{pH}=3)$ or alkalinity $(\mathrm{pH}=10) .20 \mu \mathrm{L}$ of acidic loading buffer $(\mathrm{pH}=3)$ or alkaline loading buffer $(\mathrm{pH}=12)$ was added to the conjugate pad of the DON-Chips. DON: deoxynivalenol.
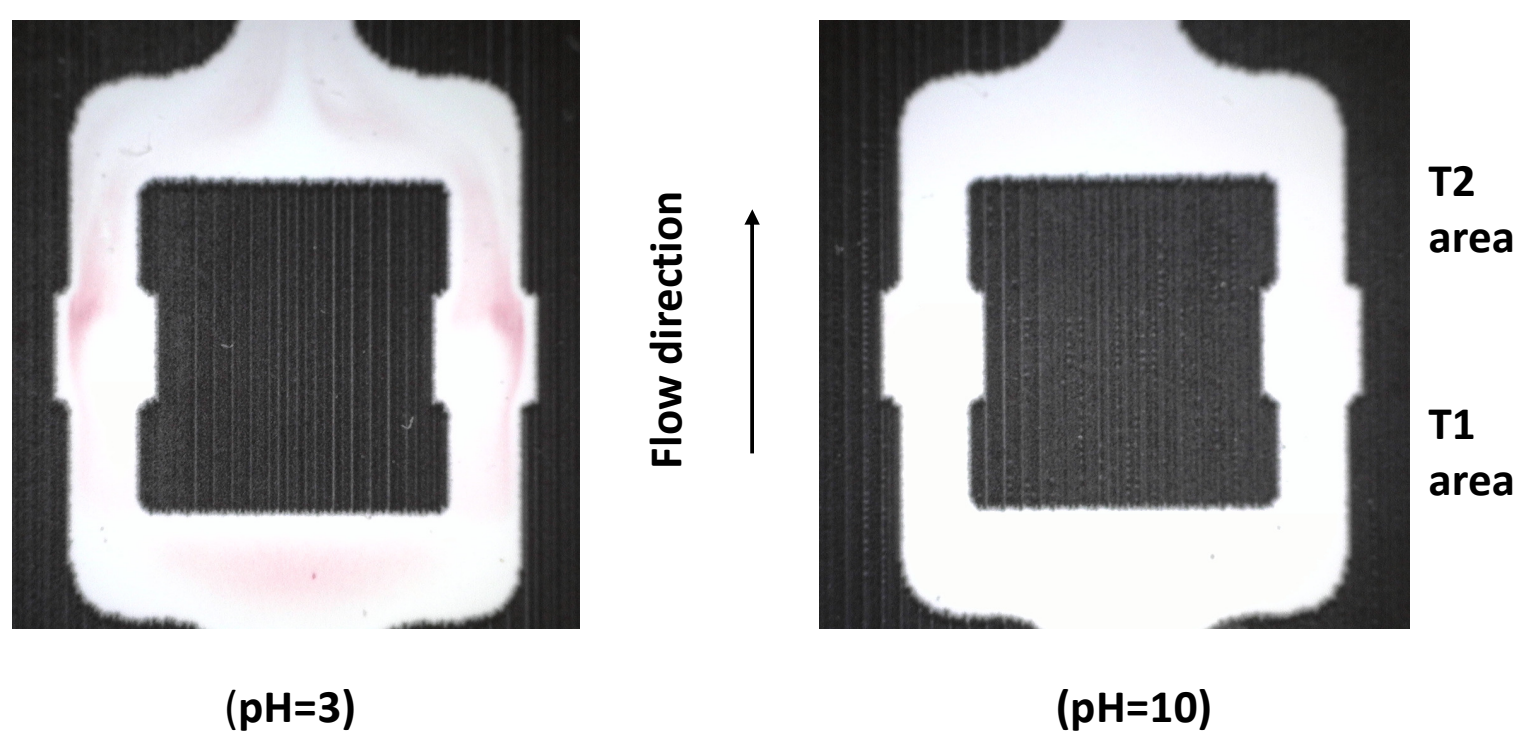
Table S1. Comparison of the data sets from the DON (deoxynivalenol) standards (1.0, 5.0 and $15 \mathrm{ng} / \mathrm{mL}$ ) detection using different calibration curves (T1, T2, T1/T2. T2/T1). Results were presented as Mean $\pm \mathrm{SD}, \mathrm{n}=4$.

\begin{tabular}{|c|c|c|c|c|}
\hline \multirow{2}{*}{$\begin{array}{l}\text { Standard } \\
(\mathrm{ng} / \mathrm{mL})\end{array}$} & \multicolumn{4}{|c|}{ Calibration curves (equations) ${ }^{1}$} \\
\hline & $\begin{array}{l}\text { T1, intra-CV }{ }^{2} \text {, } \\
\text { recovery }\end{array}$ & $\begin{array}{l}\mathrm{T} 2 \text {, intra-CV, } \\
\text { recovery }\end{array}$ & $\begin{array}{l}\mathrm{T} 1 / \mathrm{T} 2 \text {, intra-CV, } \\
\text { recovery }\end{array}$ & $\begin{array}{l}\mathrm{T} 2 / \mathrm{T} 1 \text {, intra-CV, } \\
\text { recovery }\end{array}$ \\
\hline 1.0 & $\begin{array}{l}1.11 \pm 0.08 \\
7.21 \%, 111 \%\end{array}$ & $\begin{array}{l}0.88 \pm 0.07, \\
7.95 \%, 88.1 \%\end{array}$ & $\begin{array}{l}0.94 \pm 0.07 \\
7.45 \%, 94.2 \%\end{array}$ & $\begin{array}{l}1.24 \pm 0.11 \\
8.91 \%, 112 \%\end{array}$ \\
\hline 5.0 & $\begin{array}{l}5.42 \pm 0.22 \\
4.06 \%, 108 \%\end{array}$ & $\begin{array}{l}5.24 \pm 0.17, \\
3.24 \%, 105 \%\end{array}$ & $\begin{array}{l}5.46 \pm 0.34 \\
6.23 \%, 109 \%\end{array}$ & $\begin{array}{l}6.05 \pm 0.41 \\
6.78 \%, 121 \%\end{array}$ \\
\hline 15 & $\begin{array}{l}15.41 \pm 0.41, \\
2.66 \%, 103 \%\end{array}$ & $\begin{array}{l}14.23 \pm 0.36, \\
2.53 \%, 94.8 \%\end{array}$ & $\begin{array}{l}14.19 \pm 0.52 \\
3.66 \%, 94.6 \%\end{array}$ & $\begin{array}{l}15.32 \pm 0.57 \\
3.72 \%, 102 \%\end{array}$ \\
\hline
\end{tabular}

${ }^{1}$ Calibration equations for T1, T2, T1/T2 and T2/T1 are "Y=\{130.62/[1+(X/2.42) $\left.{ }^{1.3}\right]$ $4.39\}^{*} 10^{4}, \quad \mathrm{R}^{2}=0.992 ”, \quad \mathrm{Y}=\left\{130.07-113.57 /\left[1+(\mathrm{X} / 2.91)^{1.58}\right]\right\} \quad * 10^{4}, \quad \mathrm{R}^{2}=0.995, \quad$ and $\mathrm{Y}=7.92 /\left[1+(\mathrm{X} / 0.68)^{1.57}\right]-0.016, \mathrm{R}^{2}=0.983, \mathrm{Y}=4930254-4930254 /\left[1+(\mathrm{X} /)^{1.66}\right], \mathrm{R}^{2}=0.969$, respectively.

${ }^{2}$ Intra-CV, coefficient of variation of intra-assay was calculated using the equation: $\mathrm{CV}=$ (SD/Means) $\times 100 \%$.

${ }^{3}$ Recovery ratio was calculated using the equation: Recovery $(\%)=($ Means/concentration of DON standards) $\times 100 \%$. 
Table S2. The comparison of relative slopes between T1 and T1/T2 at low concentrations (0-2 ng/mL), and between T2 and T2/T1 calibration curves at high concentrations (8-20 $\mathrm{ng} / \mathrm{mL})$.

\begin{tabular}{|c|c|c|}
\hline Signals & Equations $^{1}$ & Relative slopes $^{2}$ \\
\hline $\mathrm{T} 1$ & $\mathrm{y}=\left(\mathrm{a}+\mathrm{b}^{*} \mathrm{x}\right) * 10^{4}, \mathrm{a}=124.8 ; \mathrm{b}=-27.1 ; \mathrm{R}^{2}=0.991$ & 0.767 \\
\hline $\mathrm{T} 1 / \mathrm{T} 2$ & $\mathrm{y}=\mathrm{a}+\mathrm{b} * \mathrm{x}, \mathrm{a}=7.32 ; \mathrm{b}=-3.33 ; \mathrm{R}^{2}=0.913$ & 10.08 \\
\hline $\mathrm{T} 2$ & $\mathrm{y}=(\mathrm{a}+\mathrm{b} * \mathrm{x}) * 10^{4}, \mathrm{a}=99.3 ; \mathrm{b}=1.32 ; \mathrm{R}^{2}=0.986$ & 0.126 \\
\hline $\mathrm{T} 2 / \mathrm{T} 1$ & $\mathrm{y}=\left(\mathrm{a}+\mathrm{b}^{*} \mathrm{x}\right), \mathrm{a}=-6.75 ; \mathrm{b}=1.48 ; \mathrm{R}^{2}=0.985$ & 3.462 \\
\hline
\end{tabular}

${ }^{1}$ Calibration equations for $\mathrm{T} 1$ and $\mathrm{T} 1 / \mathrm{T} 2$ were linear fitted using the data set from $0-2$ $\mathrm{ng} / \mathrm{mL}$ standards; calibration equations for $\mathrm{T} 2$ and $\mathrm{T} 2 / \mathrm{T} 1$ were linear fitted using the data set from $8-20 \mathrm{ng} / \mathrm{mL}$ standards.

2 The relative slopes of $\mathrm{T} 1$ and $\mathrm{T} 1 / \mathrm{T} 2$ calibration equations were calculated by the equation: relative slope $=\mid(b \times$ linear range $) / y(2) \mid$.

The relative slop of $\mathrm{T} 2$ and $\mathrm{T} 2 / \mathrm{T} 1$ calibration equations were calculated by the equation: relative slope $=\mid(\mathrm{b} \times$ linear range $) / \mathrm{y}(8) \mid$. 
Table S3. Unit conversion between $\mathrm{ng} / \mathrm{mL}$ of deoxynivalenol (DON) standard and ppm of DON in the raw samples under different dilution factors $(10,100,500$, and 1000).

\begin{tabular}{|c|c|c|c|c|}
\hline \multirow{2}{*}{$\begin{array}{c}\text { Standard } \\
(\mathrm{ng} / \mathrm{mL})\end{array}$} & \multicolumn{4}{|c|}{ Raw samples (ppm) } \\
\cline { 2 - 5 } & Dilution factor & Dilution factor & Dilution factor & Dilution factor \\
& 10 & 100 & 500 & 1000 \\
\hline 0.0 & 0 & 0 & 0 & 0 \\
\hline 1.0 & 0.01 & 0.10 & 0.50 & 1.00 \\
\hline 2.0 & 0.02 & 0.20 & 1.00 & 2.00 \\
\hline 4.0 & 0.04 & 0.40 & 2.00 & 4.00 \\
\hline 8.0 & 0.08 & 0.80 & 4.00 & 8.00 \\
\hline 16 & 0.16 & 1.60 & 8.00 & 16.00 \\
\hline 20 & 0.20 & 2.00 & 10.00 & 20.00 \\
\hline
\end{tabular}


Table S4. Comparison of the DON-Chip with ELISA kit and commercial strip in terms of LOD, assay time, detection range, cost, and on-site detection capability. The data is from the manual books of commercial products (commercial products with the best parameter are chosen for the comparison). The values of LOD and detection range were uniformly converted, assuming the samples are pre-processed using the same dilution factor. DON, deoxynivalenol.

\begin{tabular}{|l|c|c|c|}
\hline Items & ELISA kit & $\begin{array}{c}\text { Commercial } \\
\text { strip }\end{array}$ & DON-Chip \\
\hline LOD, ppb (dilution factor, 10) & 10 & 50 & 4.7 \\
\hline Time per run, minutes & $\sim 120$ & $\sim 12$ & $\sim 12$ \\
\hline $\begin{array}{l}\text { Detection range, ppm (dilution } \\
\text { factor, 10-1000) }\end{array}$ & $0.02-160$ & $0.05-100$ & $0.01-20$ \\
\hline Cost, US dollar/duplicate & $\sim 5$ & $\sim 4$ & 1.94 \\
\hline On-site detection & No & Yes & Yes \\
\hline
\end{tabular}


Movie S1: Illustration of the DON-Chip fabrication and operation

Movie S2: Illustration of the DON detection principle using the DON-Chip 